\title{
As competências do bibliotecário na educação básica: reflexões de rede
}

Eliane Fioravante Garcez

\begin{abstract}
Doutoranda no Programa de Pós-Graduação em Ciência da Informação, da Universidade Federal de Santa Catarina
\end{abstract}

http://dx.doi.org/10.1590/1981-5344/1923

O artigo resulta de estudo de um modelo de gestão para bibliotecas da rede de escolas de educação básica vinculada à administração pública do Estado de Santa Catarina, desenvolvido em 2012. O estudo dessa rede, composta por mais de mil unidades escolares distribuídas em 293 municípios, além de prever a criação de 300 cargos de bibliotecário fez surgir um modelo de rede estruturado em três níveis de competência bibliotecária a partir do lugar de atuação desse profissional: a) Órgão Central da Secretaria de Estado da Educação; b) Gerências Regionais distribuídas em 36 municípios sede; $e, c)$ Unidades Escolares. O estudo mais recente do qual fizemos um recorte e apresentamos neste artigo, teve a participação de representantes dessa categoria profissional em Santa Catarina e com representantes da Secretaria de Estado da Educação. Com as ideias abordadas neste texto se pretende ampliar a discussão sobre o papel do bibliotecário quando da formação de uma rede de bibliotecas escolares no âmbito da administração pública estadual.

Palavras-Chave: Bibliotecário Escolar - Competências. Rede de Bibliotecas Escolares - Santa Catarina (Brasil) Estudo.

\section{The competences of librarian in basic education: reflections from of a network proposal}

This article results from a study of a management model for libraries in the public schools that offer basic education linked to the state of Santa Catarina (SC) Public Administration. The study was developed in 2012 and it 
comprised over a thousand schools distributed in 293 cities in the state. Besides anticipating the creation of 300 librarian positions, the study made possible the emergence of a network model structured in three levels of librarian competence starting from the work place of this professional: a) Central department of the Education Secretary of SC b) regional offices distributed in 36 cities, and, c) Schools. The latest study, from which we detached a part, had the participation of representatives of school librarians in SC and of the Education Secretary of SC. With the ideas discussed in this text, it is intended to extend the discussion about the librarian role with respect to the formation of a network of school libraries within the state public administration.

Keywords: School Librarian - Competences. School Libraries Network - Santa Catarina (Brazil) - Study.

Recebido em 18.11.2013 Aceito em 03.10.2014

\section{Introdução}

La definición de las competencias profesionales tiene diferentes utilidades y distintos destinatarios. En primer lugar, supone un ejercicio de aclariación de los límites de nuestra profesión, algo esencial en un momento en el que con la Sociedad de la Información esos límites se han desdibujado. Así, los profesionales tienen una herramienta que les ayuda en la definición de su propio perfil y en la identificación de sus puntos fuertes y débiles ante el mercado laboral. (MOREIRO GONZÁLEZ; TEJADA, 2004, p. 98).

Na última década do século XX, Waldeck Carneiro da Silva (1999) denunciava o estado de abandono da biblioteca escolar no Brasil. De lá para cá muita coisa mudou na sociedade devido, principalmente, às inovações tecnológicas que possibilitaram novas formas de acesso à leitura, à informação e ao conhecimento. Contudo, quando se olha mais atentamente para as bibliotecas, sobretudo para aquelas que integram os contextos escolares, vê-se que essas inovações ainda permanecem distantes da realidade da maioria desses espaços, principalmente daqueles dos quais depende grande parte da população em idade escolar: os espaços educacionais públicos. Por conta disso, e dentre tantas ações que precisam ocorrer para que essa realidade seja alterada, torna-se necessário que o bibliotecário, independentemente de seu lugar de atuação, se envolva com essa questão. 
A Lei 12.244/2010 (BRASIL, 2010), cuja promulgação resulta de um movimento que não é recente, é exemplo desse ato de envolver-se. Até ser aprovada ela contou com a interação de muitos sujeitos (bibliotecários e não bibliotecários) espalhados em diferentes pontos deste país. Desde então novas ações se fazem necessárias para que os contextos escolares sejam efetivamente servidos por bibliotecas e por profissionais capazes de atendê-los. Mas quais os desafios decorrentes desta lei?

Esse é o questionamento central pelo qual perpassa este texto. Por meio dele, ênfase será dada às questões em torno das competências e atribuições do bibliotecário diante da perspectiva de abertura de postos de trabalho na escola em função da Lei 12.244/2010.

Em Santa Catarina o caminho percorrido em torno desta questão levou a categoria profissional a apresentar ao governo do Estado uma proposta de criação do cargo de bibliotecário vinculado ao Quadro do Magistério e a formação de uma rede de bibliotecas. As razões e os reflexos dessas ideias serão tratados no decorrer deste artigo, que intenciona, ainda, promover uma discussão sobre o papel do bibliotecário na educação básica, registrando o envolvimento da classe profissional catarinense com este tema, envolvimento que possibilitou a construção do projeto, do qual é apresentado aqui um recorte.

Por fim, será socializada parte deste processo e as ideias em torno dele com o intuito de favorecer uma discussão acerca da institucionalização de uma rede de bibliotecas escolares no estado catarinense e noutros contextos no que diz respeito à competência profissional do bibliotecário que estará atuando nessa rede. Para alcançar tal intento o debate é tecido em quatro tópicos centrais, quais sejam: profissões e competência; competência bibliotecária: formação e atuação; rede escolar: um lugar para o bibliotecário atuar; e, as competências do bibliotecário no estudo de modelo de rede de bibliotecas para a educação básica em Santa Catarina.

As questões que norteiam as discussões presentes nestes tópicos são trazidas ao leitor buscando-se promover a reflexão tanto sobre os limites da profissão do bibliotecário, como apontado na epígrafe deste texto, quanto nas possibilidades de sua ampliação. Entende-se que, em se tratando da educação básica, a centralidade da ação na técnica profissional não basta. Essa ação precisa ser conciliada com outras necessidades da comunidade escolar, o que demanda novas atribuições e competências ao profissional bibliotecário. A ampliação da função do bibliotecário no contexto escolar não descaracteriza essa profissão, ao contrário, a faz avançar e crescer nesse contexto tão particular de base educativa.

\section{0 desencadeamento das ações no contexto catarinense}

Em Santa Catarina as ações para a melhoria das bibliotecas escolares na rede estadual não são recentes. No entanto, dentre elas será dada ênfase, neste texto, a três episódios que demarcam importantes momentos dessa trajetória. 
O primeiro episódio ocorreu em 2003 com a publicação da Portaria 003/SED de 04/04/2003, (SANTA CATARINA, 2003), no contexto de readaptação de professores excedentes do magistério estadual às bibliotecas escolares. Foi nesse momento, a partir da intervenção da categoria bibliotecária, que o Governo acenou para a possibilidade de transformar 300 cargos de Assistente Educacional do Quadro do Magistério em cargos de bibliotecário. Tal intenção não se concretizou, mas de certa forma foi motivadora de outros episódios, como a proposta que se tem atualmente para as bibliotecas escolares.

O segundo episódio girou em torno do Projeto de Lei Complementar PLC/0039.0/2010, de 20 de julho de 2010, que objetivou criar o cargo de bibliotecário para atuar nas escolas e "(...) solucionar a falta de profissionais, com formação específica na função de bibliotecário nas escolas públicas estaduais (...)" (SANTA CATARINA, 2010). Nesse PLC é prevista a alteração da Lei no 1.139/1992, que dispõe sobre cargos e carreiras do magistério público estadual, incluindo nela o cargo de bibliotecário. Vê-se que a ideia de iniciativa do Executivo de vincular o cargo de bibliotecário ao Quadro do Magistério, ocorrida em 2003, é aqui retomada. Apesar de aprovado, o PLC/0039.0/2010 foi posteriormente declarado inconstitucional por tratar de "(...) matéria de iniciativa exclusiva do Governador do Estado, a quem compete iniciar o processo legislativo." (SANTA CATARINA, 2011). A esse argumento pela inconstitucionalidade juntou-se outro: sem a anuência prévia do Governo o projeto teria problemas de orçamento no Executivo.

Em 2012, por conta da Lei $12.244 / 2010$ e pela presença de um bibliotecário na equipe de gestão da Secretaria de Educação, se deu o terceiro dos episódios anteriormente mencionados. Nesse momento as discussões com a Secretaria são retomadas por meio de uma comissão ${ }^{1}$ incumbida de estudar e apresentar uma proposta ao Executivo. Essa comissão, representativa dos bibliotecários, resgatou o que a categoria tinha, até então, discutido e reunido em documentos. Do que havia permaneceu a vinculação do cargo de bibliotecário ao Quadro do Magistério, a alterar a Lei no 1.139/1992, e o quantitativo de 300 cargos. A reestruturação ficou por conta de um modelo de rede de bibliotecas (prevendo-se a distribuição do bibliotecário nela com um rol de atribuições específicas), e a implementação de quadro salarial e de carreira. $\mathrm{Na}$ reestruturação a grande novidade deu-se pela distribuição dos 300 cargos em três distintas áreas de atuação profissional: a) unidade central da Secretaria de Estado da Educação (SED); b) Secretarias de Desenvolvimento Regional (SDR) - unidades descentralizadas do Executivo, ou nas Gerências Regionais de Educação (GEREI) - unidades setoriais da SED; e, c) unidades escolares distribuídas em 293 municípios.

Esse modelo de rede apresentado à Secretaria de Educação no início de 2013 descreve as atribuições do bibliotecário agrupadas em

\footnotetext{
${ }^{1}$ Participaram dessa comissão Gyance Carpes (CRB-14), José Paulo Speck Pereira (ACB), Gisela Eggert-Steindel (FAED/UDESC) e a autora deste artigo.
} 
conformidade com os três locais que esse profissional poderá atuar, definindo as funções de: gestão, técnica e técnica-pedagógica.

Mediante alguns dos fatos desencadeadores da vinculação do

cargo de bibliotecário escolar ao Quadro do Magistério, serão apresentadas no próximo tópico outras questões referentes a essa vinculação, além daquelas relacionadas à competência bibliotecária no que diz respeito à expansão das funções de atuação desse profissional.

\section{Profissões e competência}

As profissões são criadas por necessidades provenientes de uma sociedade em constante mudança. Sendo assim, a manutenção ou a sobrevivência de uma profissão nesse contexto transitório exige de seus profissionais adaptações contínuas às novas exigências sociais, um quadro que reflete diretamente na formação desses profissionais.

Entre as diferentes profissões observa-se ao mesmo tempo, conflitos e uma situação de interdependência. Como as tarefas profissionais não são permanentes, as profissões competem entre si num sistema de interações, ou numa ecologia, que vai redesenhando-as a partir das influências que exercem e recebem uma das outras e do meio social. (CUNHA; CRIVELLARI, 2004).

Para Cunha (2006, p. 142), as profissões diferenciam-se entre si essencialmente por serem constituídas "(...) por grupos de pessoas com conhecimentos e competência específicas (...)." A partir de Cunha; Crivellari (2004) pode-se afirmar que as competências profissionais modificam-se a partir das interações que os sujeitos (profissionais e não profissionais) estabelecem uns com os outros. Logo, são esses sujeitos que mudam a sociedade, criam e respondem as demandas por novos serviços, novos produtos e por novos profissionais.

Segundo Freidson (1998, p. 246) os profissionais realizam um trabalho que "requer conhecimento teórico, competência e discernimento que as pessoas comuns não possuem, podem não compreender completamente e não podem avaliar prontamente." Sales (2004) e Garcez; Cunha (2011) mencionam evidências dessa situação.

Mas o que se entende por competência profissional? A partir de Moreiro González; Tejada (2004) pode-se inferir que são habilidades, atitudes, destrezas, um conjunto de conhecimentos desenvolvidos no intelecto do profissional pelas interações que estabelece com outros sujeitos da formação à atuação profissional, incluindo aí as relações que se estabelecem na vida cotidiana. Sendo assim, a competência profissional está atrelada ao conhecimento desenvolvido e devolvido para uma área profissional específica, portanto está na cabeça do profissional.

Ainda, de acordo com esses autores não há como se referir à competência profissional sem a vincular a um posto de trabalho. O posto de trabalho aqui discutido está na educação básica - na escola -, nascedouro do processo educativo, ambiente que sedimenta a cultura de um povo, incluindo nele a cultura de biblioteca, a cultura de uso da 
informação, por isso merecedor de especial atenção do Governo e da Ciência da Informação.

Mesmo que ainda fortemente centrada na técnica da organização da informação, a formação do bibliotecário tem incorporado outras preocupações, como aquelas que perpassam questões relacionadas ao uso dessa informação, por exemplo: os estudos sobre o usuário, a educação desse usuário, a orientação sobre o funcionamento das unidades de informação, sobre os tipos de suportes informacionais e serviços oferecidos. Dessa forma, hoje, parece que oferecer orientação para o uso da informação já não é suficiente. Há uma demanda por um serviço de capacitação para além do acesso à informação; está-se falando em oferecer aos alunos condições para que desenvolvam competências para gerarem algo novo - um conhecimento novo. Sobre isso são pertinentes as considerações de Garciarena; Conforti (2011), quando afirmam que:

No son sólo la eficiencia y la rapidez con que se entregan los materiales al usuario lo importante, sino la calidad de la formación que se le brinda, el desarrollo de sus habilidades y destrezas en la búsqueda, el acceso y la utilización de fuentes físicas y virtuales y en la selección de la información pertinente y la producción de conocimiento (alfabetización informacional). (GARCIARENA; CONFORTI, 2011, p. 150)

O termo alfabetización informacional utilizado pelas autoras equivale à information literacy, conceito cunhado nos Estados Unidos, na década de 1970, pelo bibliotecário Paul Zurkowski (DUDZIAK, 2003). Ainda, de acordo com Dudziak (2003, p. 24), naquela época "antevia-se uma realidade de mudanças nos sistemas de informação e no papel exercido pelos bibliotecários."

Outro termo equivalente à Information literacy é competência informacional, tradução de Bernadete Campello (2003), para quem a necessidade do aluno desenvolver tal competência evidencia a função educativa do bibliotecário, fortalece a presença desse profissional na escola e a sua área de atuação. Hoje, mais do que ontem, além da necessidade de acesso à informação, os alunos precisam receber orientação quanto ao uso de fontes, quanto ao uso da informação contida nelas, enfim... eles carecem de melhores condições materiais e de orientação para usufruírem delas com mais proveito. Quanto a isso, sábias são as palavras de Sales (2004, p. 44, grifo meu) quando afirma que "somente oferecer a informação sobre documentos e seus conteúdos, já não basta. É necessária a certeza de que ela alcançará seu destino: o entendimento de quem a busca."

Diante dessas considerações cabe a pergunta: Será o papel do bibliotecário o de educador?

A escassez de bibliotecas escolares nas instituições de ensino brasileiras e de políticas públicas voltadas para essas unidades têm desencadeado discussões relativas à disponibilidade e ao uso da informação nesses espaços e aos seus reflexos na formação dos alunos. 
Nesse sentido, e pelas necessidades apontadas por Campello (2003) e Sales (2004), pode-se afirmar que há uma demanda pela reconfiguração da forma como a escola e seus profissionais exercem os seus papéis, o que de certa forma tem repercussão direta na formação e nas competências profissionais.

No que tange aos profissionais bibliotecários essa preocupação é abordada por Dudziak (2003) ao anunciar também o conceito de Information Literacy Education, afinal os profissionais precisam se preparar para atender a demanda informacional na escola e fora dela por isso a necessidade de organizar e disponibilizar a informação e ensinar pessoas a utilizá-la. Se esses conceitos são retomados com a Lei $\mathrm{n}^{\circ}$ 12.244/2010 (BRASIL, 2010), com ela permanece ainda o desafio à classe bibliotecária e aos gestores públicos de pensarem na criação e no funcionamento de uma estrutura de bibliotecas que dê amparo a tais concepções. Sendo inquestionável o valor da biblioteca escolar na formação dos alunos a questão aqui colocada está centrada no como fazer funcionar essa ideia de rede e no que fazer para que de fato ela ocorra. Sabe-se que a implantação de uma rede de bibliotecas escolares envolve questões de compromisso e de interesse do poder público. Envolve, também, é certo, a presença de um corpo profissional que a faça funcionar. Envolve, portanto, questões éticas de gestão pública, de formação e de atuação profissional.

É sabido que em Santa Catarina há 1.112 unidades escolares ${ }^{2}$, cada uma delas com realidades (social, econômica, cultural, política) bastante distintas. Há, ainda, outros diferenciais: número de integrantes na comunidade escolar, se escola básica, desdobrada, isolada etc. Portanto, é preciso estar atento a tais detalhes quando da distribuição dos bibliotecários nessas unidades, sobretudo, quando se atenta para o fato de que em meio a tantas diferenças, existe algo em comum entre elas: em nenhuma há bibliotecário.

\section{Competência bibliotecária: formação e atuação}

Em estudo recente foi proposto ao poder público catarinense a formação de uma rede de bibliotecas escolares estando previstas nessa rede a criação de 300 cargos de bibliotecário e a distribuição desse quantitativo em três pontos de atuação determinadores de distintas atribuições.

Para tornar-se realidade essa rede escolar precisa contar com a presença de diferentes profissionais (bibliotecários, professores, auxiliares de biblioteca, diretor de escola, supervisor, orientador educacional entre outros). Tendo em vista o foco deste trabalho, dar-se-á ênfase, nesse contexto, à atuação do bibliotecário por se considerar que a inserção desse profissional na escola é fundamental para o melhor funcionamento das redes de ensino.

\footnotetext{
${ }^{2}$ Dados informados pela Secretaria de Estado da Educação, à comissão encarregada do estudo realizado em 2012.
} 
Tendo em vista o número de escolas que integram a estrutura educacional básica subordinada ao governo do Estado de Santa Catarina, para manter funcionando uma rede de bibliotecas faz-se necessário estabelecer as atribuições de todos os profissionais envolvidos. Quanto às do bibliotecário, exploradas ao longo deste texto e elencadas no tópico 6, é intenção dar destaque àquelas que o bibliotecário precisará para atuar na escola. Trata-se de atuação mais direta na formação dos alunos, o que exige desse profissional, conforme Sales (2004) e Garcez; Cunha (2011), novas competências que talvez o aproximem daquelas do educadorprofessor. E isso nos remete à questão da formação do profissional, da criação do cargo na estrutura do executivo estadual e da vinculação deste cargo ao Quadro do Magistério.

O atendimento à demanda por competência informacional (DUDZIAK, 2003; CAMPELLO, 2003), também está atrelado ao modelo educacional que forma os profissionais que estão na escola, o bibliotecário e aos cursos de formação continuada. Sales (2004, p. 51) ao tratar sobre as responsabilidades pedagógicas do bibliotecário e as suas implicações na formação, no desenvolvimento profissional e no mercado de trabalho, afirma que: "o bibliotecário escolar pode ser o agente mediador e mais experiente (...) com quem os alunos podem aprender mais, a partir da sua atuação pedagógica."

Em pesquisa sobre as práticas educativas de bibliotecários em escolas de ensino básico Campello (2010, p. 186) concluiu que o bibliotecário "(...) embora tendo consciência de seu papel educativo, não deu ainda o salto para a ação pedagógica mais ampla, que possa contribuir para a formação de usuários competentes na busca e no uso de informação." Uma das possíveis respostas para essa situação foi apontada por Garcez; Cunha (2011) ao discorrerem sobre o envolvimento do bibliotecário catarinense com a pesquisa escolar. As autoras revelam que bibliotecário e professor não acompanham o aluno nas suas necessidades de pesquisa, e que tais atitudes estão ligadas às concepções que têm do que seja pesquisa escolar imbricadas na formação. À lentidão do bibliotecário à ação pedagógica da qual se refere Campello (2010) deve-se relacionar também dados de cunho quantitativo como a desproporção entre o número de bibliotecários nas escolas, o de integrantes na equipe da biblioteca e o de alunos a serem atendidos.

Voltadas para outro contexto, mas tendo como foco a mesma questão, Garciarena; Conforti (2011) ao discorrerem sobre as competências do bibliotecário escolar salientam que a biblioteca é responsabilidade de todos. As autoras levantam questionamentos sobre algo percebido pelo bibliotecário brasileiro, mas que poucos daqui do Brasil registraram. Vejamos:

(...) ¿qué ocurre cuando el bibliotecario llega por primera vez a la institución educativa? ¿Quién acompaña su desarrollo profesional desde el asesoramiento? ¿Hay colegas dentro de la misma organización que lo ayuden? ¿Qué conocimientos tienen los directivos para supervisar, asesorar, evaluar las 
prácticas bibliotecarias y abordar y discutir los nuevos perfiles como agentes de cambio? (GARCIARENA; CONFORTI, 2011, p. 152).

Vê-se que os questionamentos arrolados pelas autoras são fundamentais, afinal o fazer bibliotecário precisa da cumplicidade de outros, imbrica-se com outros afazeres do/no meio escolar.

No desenvolvimento de suas ações o bibliotecário escolar exerce funções técnicas e pedagógicas. O pouco uso da biblioteca, o espaço físico - insuficiente para acolher os usuários, e o escasso acervo conduzem, aos poucos e naturalmente, o bibliotecário às atividades que de certa forma contribuem para suprir essas lacunas como as atividades culturais e de incentivo ao uso da biblioteca e à leitura, projetos com professores, entre outras. Daí se inicia a sua aproximação com as práticas de ensino e de aprendizagem escolar, que o levam a se envolver com o ensino dos "segredos" do acesso à informação nas diferentes fontes, de como o usuário pode obter a informação que necessita. Percebe-se, portanto, que as atividades do bibliotecário vão além das técnicas. Envolvem a iniciação do aluno ao uso das fontes de informação e da biblioteca.

Mas qual a opinião dos bibliotecários sobre essa situação? Afinal, por força do seu local de atuação - a escola, e independentemente desta pertencer à esfera estadual, municipal ou federal, o bibliotecário que atua numa rede escolar deve estar vinculado ao Quadro do Magistério juntamente com professores, orientadores educacionais, supervisores dentre outros, ou ao Quadro Civil (técnico-administrativo) ao lado de engenheiros, administradores, psicólogos, economistas e outros? O que favorece ao próprio bibliotecário, à escola e ao aluno, o seu pertencimento num e não noutro quadro? Há diferenças de ordem prática no exercício do seu papel social estando ele vinculado em um e não em outro quadro? E quanto às questões salariais, haveria diferenças pertencendo a um ou a outro quadro? Por certo que sim. A gratificação por Dedicação Exclusiva (DE) é uma delas. Se essas são razões para a demora da criação do cargo de bibliotecário no estado de Santa Catarina, por qual motivo os dirigentes da pasta da educação propuseram, em 2003, esse caminho da vinculação do cargo ao Quadro do Magistério?

O fato é que essas discussões nos remetem a uma necessidade que é fundante para a sociedade: a garantia de uma educação pública de qualidade. Necessidade que traz à tona a demanda por profissionais "feitos" pelas instituições formadoras e pela experiência, esta última marcada pela oportunidade de atuar.

Sobre essa "feitura" resgatamos as palavras de Diniz (2001) ao dizer que:

o desempenho profissional orienta-se via de regra menos por um corpo de conhecimento abstrato e sistematizado do que por um conjunto de 'receitas' práticas e decodificadas que, desenvolvidas através do trato direto com problemas 
concretos, formam a 'sabedoria convencional' da profissão. (DINIZ, 2001, p. 170).

Segundo Garciarena; Conforti (2011, p. 154, grifo meu) a construção da formação do bibliotecário se dá em quatro instâncias: "formación inicial; Inserción en la institución educativa; perfeccionamiento en servicio; formación continua o permanente." Ainda, conforme as autoras:

(...) se pueden distinguir dos etapas: la formación propiamente dicha e institucionalizada, y la profesionalización, es decir, las capacidades alcanzadas en el desempeño y de la práctica misma. Circunstancialmente ambas se entrecruzan. (GARCIARENA; CONFORTI, 2011, p. 154).

Diante disso, ao atuar na escola, o bibliotecário precisará de outros conhecimentos além daqueles advindos de sua formação profissional. Parece-nos que dele serão exigidos conhecimentos do planejamento pedagógico da instituição, das disciplinas, dos alunos, dos professores, dos gestores da escola e das famílias dos alunos. Ou seja, da relação da biblioteca com questões próprias do meio escolar. Esse conhecimento deve estar amparado nas normas que estabelecem o funcionamento da escola (regulamentos, Projeto Pedagógico (PPP), regimentos, etc.), nos programas de leitura, programas de biblioteca, programas do governo federal, como o Programa Nacional Biblioteca na Escola (PNBE) entre outros. Tais conhecimentos ajudarão o bibliotecário a entender melhor 0 papel da biblioteca, o seu próprio papel e o de ambos na escola e a vinculação destes com a sociedade. Portanto, o conhecimento advindo da formação e da atuação escolar e da vivência o ajudará nas práticas interativas com aqueles que estão na escola e no entorno desta.

O projeto de rede de bibliotecas em Santa Catarina prevê três papéis bastante diferenciados para o bibliotecário: gestor, gestor-técnico, e técnico-pedagógico. Isso mostra uma compreensão de que cada bibliotecário investido nesses papéis tem distintas atribuições, lida com contextos diferenciados (Secretaria da Educação, suas regionais e escolas) cujo objetivo comum a todos eles é atender o sujeito aprendente que está na escola.

\section{Rede escolar: um lugar para o bibliotecário atuar}

O Manifesto A Library for Every School (2010, p. 3, tradução da autora) associa a superação dos desafios do século XXI ao papel do bibliotecário na escola, por ser esse local "(...) crucial para o progresso econômico e social de todos os países." Esse manifesto dá força aos dispositivos legais (Constituição Federal e estadual, Lei de Diretrizes e Bases da Educação Nacional e a Lei 12.244/2010) que responsabilizam o Estado pela qualidade do ensino associado à criação e dinamização de bibliotecas nas instituições de ensino. 
Em 2011, portanto, após a aprovação da Lei 12.244/2010, o Conselho Regional de Biblioteconomia de Santa Catarina (CRB-14) consultou professores, diretores de escola e gerentes de educação sobre a necessidade de suas unidades escolares contarem com bibliotecas e bibliotecários.

Nos depoimentos colhidos ficou evidente a carência de bibliotecas, mostrando que o discurso de Silva (1999) ainda é atual. Para os profissionais consultados:

O bibliotecário é visto como um profissional com uma competência específica que o credencia para atuar na biblioteca, um organizador de acervos, com ênfase na leitura, que permite $o$ incentivo à aprendizagem;

A organização da biblioteca é fundamental para o acesso ao acervo;

A biblioteca deve servir à comunidade escolar e não apenas ao aluno;

Com o bibliotecário será possível atender uma rede de unidades escolares;

A leitura é fundamental para a inclusão social e seu incentivo está ligado a uma orientação profissional competente;

A necessidade de bibliotecário nas escolas não é reivindicação recente.

As afirmações acima elencadas reforçam as teorias de Freidson (1998, p. 211) quando afirma que "na base do profissionalismo (...) está o conhecimento e a competência especializados considerados como valiosos para a vida humana." Os depoimentos além de revelarem as aspirações dos gestores quanto ao papel da biblioteca e do bibliotecário demonstram que a biblioteca escolar não deve ser preocupação e responsabilidade única do bibliotecário e ao poder público deve-se cobrar a parte que lhe cabe.

\section{As competências do bibliotecário em estudo de modelo de rede de bibliotecas para a educação básica em Santa Catarina}

Afinal, quais deveriam ser as competências do bibliotecário que atua na escola? O que muda para ele quando atua numa rede de bibliotecas escolares? Será que ao atuar na educação básica o bibliotecário torna-se especialista nessa área?

Lembram Cunha; Crivellari (2004, p. 42) que "as especializações profissionais aparecem quando existe uma diferenciação na estrutura que forma as profissões: diferenciação do tipo de clientes, do local de trabalho etc." O aparecimento de uma crescente demanda por bibliotecas e 
bibliotecários na escola viabilizará um exercício profissional, bastante específico, ainda pouco explorado pelo bibliotecário. Dessa atuação, entende-se, devem surgir as possibilidades de um novo desenho ou redesenho de suas atribuições e novas competências.

Moreira González; Tejada (2004, p. 98) compreendem que a definição de competência é importante, porque a partir dela o profissional passa a contar com "una herramienta que les ayuda en la definición de su propio perfil y en la identificación de sus puntos fuertes y débiles ante el mercado laboral." Sales (2004, p. 55) afirma que "o bibliotecário precisa interpretar sua ação" enfatizando que esse profissional precisa estar atento, precisa pensar no conjunto de ações do seu fazer. É também a partir daí que, para esse autor, as competências profissionais são atualizadas.

Dito isso, passa-se a exibir o rol de atribuições do bibliotecário no projeto de rede apresentado à Secretaria de Educação de Santa Catarina. Essas atribuições foram concebidas e agrupadas conforme três locais de atuação desse profissional: Órgão Central, Unidades Regionais e Unidades escolares.

Desses locais originam-se os níveis de atuação: gestão, técnico e técnico-pedagógico, cujos detalhamentos são apresentados a seguir através dos campos: Lotação, Função, Descrição sumária e Descrição detalhada do cargo.

Apresenta-se aqui parte do resultado do estudo realizado pela Comissão que concebeu esse modelo de rede, intentando-se, a partir dele, abrir novas frentes de discussão. As expressões "Descrição sumária do cargo" e "Descrição detalhada do cargo", utilizadas para tal detalhamento, equivalem às "atribuições" referentes a cada cargo apresentado a seguir.

\section{1)Lotação: Órgão central. Função: Gestão}

Descrição sumária do cargo: Participar do planejamento das decisões da Secretaria de Estado da Educação voltadas às políticas de leitura e uso da informação nas escolas. Manter estreita interlocução com os bibliotecários lotados nas Secretarias de Desenvolvimento Regional - SDR -, representando-os na Secretaria de Educação.

Descrição detalhada do cargo:

1. Definir políticas de atuação do bibliotecário escolar na rede estadual de bibliotecas escolares junto à Secretaria de Estado da Educação;

2. Planejar a atuação da rede de bibliotecas em nível local, regional e estadual;

3. Promover, de forma integrada, o planejamento da política de seleção e de aquisição de acervo na unidade central e nas bibliotecas das escolas; 
4. Elaborar, de forma participativa, as políticas dos serviços das bibliotecas, definindo objetivos e prioridades de acordo com os diferentes contextos das unidades escolares;

5. Definir políticas de acesso à informação nas bibliotecas escolares;

6. Desenvolver diretrizes para a prática da pesquisa escolar e técnica bibliográfica;

7. Incentivar o desenvolvimento de projetos de incentivo à leitura e atividades culturais;

8. Interagir com os bibliotecários lotados nas Secretarias de Desenvolvimento Regional - SDR - e nas unidades escolares conhecendo seus diferentes contextos a fim de apoiar as atividades meio e fim da rede de bibliotecas escolares;

9. Planejar a política de tratamento e organização do acervo (catalogação, classificação, indexação) das bibliotecas escolares;

10. Elaborar diretrizes de disseminação da informação nas bibliotecas escolares;

11. Criar políticas de seleção, remanejamento, preservação, e descarte do acervo no âmbito das bibliotecas das unidades escolares da rede estadual de educação;

12. Participar da elaboração da política orçamentária incluindo as necessidades da rede de bibliotecas escolares.

\section{2) Lotação: Unidades Regionais (SDR ou GEREI). Função: Gestão-Técnica}

Descrição sumária do cargo: Assessorar, no que tange às questões técnicas e gerenciais, os bibliotecários com atuação nas unidades escolares integrantes das Secretarias de Desenvolvimento Regional - SDR - ou das Gerências Regionais de Educação - GEREI, bem como representar esses profissionais perante o Órgão Central.

Descrição detalhada do cargo:

1. Participar da definição de políticas de atuação do bibliotecário da rede de bibliotecas escolares junto à Secretaria de Estado da Educação;

2. Manter-se informado sobre as condições das bibliotecas das unidades escolares vinculadas à Secretaria de Desenvolvimento Regional - SDR - pela qual é responsável; 
3. Participar dos cursos, reuniões, palestras e demais eventos relacionados à sua área de atuação;

4. Participar, quando convidado, dos encontros e reuniões promovidos pela Secretaria de Estado da Educação;

5. Manter-se informado das condições de trabalho dos bibliotecários das unidades escolares vinculadas à Secretaria de Desenvolvimento Regional - SDR -, em que é lotado;

6. Representar perante o Órgão Central os bibliotecários lotados nas unidades escolares vinculadas à Secretaria de Desenvolvimento Regional - SDR - em que é lotado;

7. Assessorar os bibliotecários em questões técnicas;

8. Colaborar com o Órgão Central no tocante à definição e execução da política de seleção, remanejamento, preservação, e descarte do acervo no âmbito das bibliotecas das unidades escolares da rede estadual de educação;

9. Participar da elaboração das políticas dos serviços das bibliotecas, respeitando os diferentes contextos;

10. Participar da definição de política de acesso à informação nas bibliotecas escolares;

11. Manter estreita interação com os demais bibliotecários lotados nas Secretarias de Desenvolvimento Regional SDR - para a melhor consecução das atividades meio e fim da rede de bibliotecas escolares;

12. Desenvolver diretrizes para a prática da pesquisa escolar;

13. Participar do planejamento da política de tratamento e organização dos acervos (catalogação, classificação, indexação) das bibliotecas escolares;

14. Executar atividades técnicas voltadas ao controle, tratamento e organização dos acervos (catalogação, classificação, indexação) das bibliotecas escolares;

15. Participar da elaboração das Diretrizes de disseminação da informação no âmbito das bibliotecas das unidades escolares;

16. Participar da elaboração da política orçamentária integrando nela a rede de bibliotecas escolares. 


\section{3) Lotação: Unidades Escolares. Função: Técnico- pedagógica}

Descrição sumária do cargo: Desenvolver atividades de incentivo à leitura, de difusão de informações nas unidades escolares, envolvendo-se com as atividades curriculares e extracurriculares da escola, atendendo também a comunidade local.

Descrição detalhada do cargo:

1. Apoiar e intensificar a consecução dos objetivos educacionais definidos na Proposta Curricular do Estado de Santa Catarina e no Projeto Político Pedagógico da escola;

2. Oferecer à comunidade escolar oportunidade de vivências destinadas à produção e uso da informação voltada ao conhecimento, à compreensão, à imaginação e ao entretenimento;

3. Desenvolver serviços de orientação ao leitor;

4. Promover o acesso às fontes de informação nos suportes impresso e eletrônico;

5. Apoiar e orientar os alunos para que desenvolvam as habilidades de uso da informação independentemente da forma e do suporte em que esteja registrada;

6. Organizar atividades que incentivem a tomada de consciência cultural e social, bem como a sensibilidade, promovendo exposições, saraus, concursos, oficinas, palestras e outros, em conformidade com a Proposta Curricular do Estado de Santa Catarina, com o Projeto Político Pedagógico da Escola e com a cultura local;

7. Trabalhar em conjunto com os alunos, professores, administradores e familiares, para o alcance final da missão e objetivos da escola;

8. Atuar em rede com os demais bibliotecários, promovendo a cooperação, o compartilhamento e o aperfeiçoamento do uso de informação na escola e fora dela;

9. Dar sugestões para a compra de documentos, visando a sua constante atualização;

10. Participar da elaboração da política de seleção do acervo;

11. Incentivar a cooperação entre os diferentes atores da comunidade escolar e outros grupos da comunidade onde a biblioteca está inserida;

12. Auxiliar professores e alunos na pesquisa escolar; 
13. Promover atividades de ação cultural;

14. Participar das reuniões pedagógicas e demais atividades desenvolvidas pela escola;

15. Trabalhar na inclusão da biblioteca escolar nas atividades pedagógicas;

16. Participar das reuniões promovidas pela escola, pela Secretaria de Desenvolvimento Regional - SDR - e pela Secretaria de Educação do Estado;

17. Participar de cursos de formação continuada.

Por meio desse detalhamento parece evidente que o papel do bibliotecário que atuará na escola não poderá ser o mesmo daquele que atuará nas unidades regionais ou no órgão central. Senão vejamos:

O bibliotecário escolar está imerso no ambiente educativo o qual exige uma constante interlocução com crianças e jovens. Esses sujeitos em aprendizagem manifestam necessidades de informação em diferentes graus de intensidade provenientes do estágio, singular, que vivenciam, quer escolar, quer pelas transformações etárias. Certamente para o bibliotecário que atua noutro tipo de biblioteca, noutro tipo de contexto e de público, essa exigência interativa será menos intensa. Se, é nesse período que os futuros bibliotecários, da futura rede de bibliotecas escolares de Santa Catarina, precisarão ensinar alunos e professores a utilizar as fontes de informação, é também nesse período que mais facilmente será despertado no aluno o gosto pela leitura, o gosto pela pesquisa, o gosto por biblioteca, o gosto pelo estudo. Esse envolvimento, essa proximidade com 0 aluno e com os seus interesses fortalece a compreensão de que na escola a função do bibliotecário é técnicopedagógica. Ou, ainda, será mais pedagógica do que técnica, já que a ênfase da atividade técnica (catalogação, classificação e indexação) ficará sob a responsabilidade dos bibliotecários que atuarão nas 36 SDRs?

A escola é ambiente fundamental na vida dos indivíduos e a biblioteca escolar é fundamental nesse ambiente pela possibilidade de "plantar" neles, desde cedo, o gosto pela leitura, de oferecer-lhes condições para o desenvolvimento de competências para o uso da informação. A partir do ambiente escolar os jovens continuarão seus estudos e/ou irão para o mercado de trabalho, percorrerão novos caminhos. No entanto, ainda faltam olhares mais atentos para que a escola e a biblioteca escolar consigam desempenhar melhor os seus papéis.

A partir de Garciarena; Conforti (2011) vê-se que o destino das bibliotecas escolares está nas mãos de muitos, porém à margem de bibliotecários. No contexto europeu, de onde falam essas autoras, assim como no Brasil, o bibliotecário ainda permanece distante da biblioteca escolar. Macedo (2005), ao promover um debate sobre a biblioteca escolar brasileira, nos chama a atenção sobre a falta de atenção do 
governo e dos professores para com esse espaço, e sobre um perfil profissional bibliotecário necessário para esse ambiente - o de próatividade. Seguem suas ideias:

La relación director-bibliotecario está condicionada por el conocimiento del primero acerca de la misión de la biblioteca, pues es él quien define las políticas institucionales, la distribución del presupuesto y subsidio asignados y quien da forma final al proyecto educativo de la escuela. (GARCIARENA; CONFORTI, 2011, p. 153).

(...) número considerável de professores e de autoridades governamentais de alto escalão, por vezes, não está voltado para a importância de se providenciarem ambientes adequados de biblioteca escolar, dotados de centros dinâmicos de aprendizagem e informação, obrigatoriamente contando com a presença ou a supervisão de bibliotecários pró-ativos. (MACEDO, 2005, p. 333-334).

A implantação de uma lei de bibliotecas, como proposto pela Lei 12.244/10 (BRASIL, 2010), lida com esses resquícios advindos de um traço cultural que precisa ser trabalhado e superado para benefício das futuras gerações. A vinculação do bibliotecário, um bacharel, ao Quadro do Magistério também precisa ser trabalhada, discutida, vislumbrada numa prática cotidiana escolar.

Será que as práticas vivenciadas pelo bibliotecário no cotidiano escolar somadas às investigações de Campello (2010) e de Sales (2004) dentre outros, associadas às questões trazidas por Freidson (1998) no tocante à sociologia das profissões, dão pistas de a vinculação do bibliotecário ao Quadro do Magistério ser a mais acertada? Qual das alternativas traria mais benefício aos bibliotecários escolares: vincular o cargo ao Quadro Civil ou ao Quadro do Magistério? Qual a que melhor se aproxima dos discursos dos gestores (públicos e privados), professores e bibliotecários ao defenderem uma educação de qualidade a ser dinamizada pela ação de profissionais para abrir novos caminhos de acesso à leitura, à informação e ao conhecimento? Quadro do Magistério ou Quadro Civil? Em qual deles se daria uma melhor interlocução entre bibliotecários e agentes educacionais (diretores, professores, supervisores e orientadores educacionais), sendo essa interlocução fundamental para que o aluno utilize a biblioteca e tenha acesso à informação?

\section{Considerações finais}

Muitas "forças" interferem no ambiente educacional atingindo as bibliotecas existentes nesse ambiente e interferindo no processo de criação de novas unidades de informação. São influências de cunho político, econômico, ideológico que alcançam a todos e interferem na forma como os sujeitos compreendem o mundo e agem nele. Disso, 
resume-se que também há uma influência recíproca entre as ações dos sujeitos entre si e o ambiente em que estão inseridos.

A valoração da biblioteca escolar e da profissão do bibliotecário recebe influência dessas "forças" e da forma do agir/influenciar os outros e o mundo. Logo, quanto maior o número de bibliotecários envolvidos nos debates sobre a situação das bibliotecas escolares maiores serão as chances de se ter mais e melhores bibliotecas, com mais crianças, jovens e adultos tendo oportunidades de resolver suas necessidades de informação.

Sendo assim, a presença do bibliotecário na escola demandará novas interlocuções com os demais envolvidos com a educação, dentro e fora da escola, aqui incluindo a sua categoria representativa e as instituições formadoras desses profissionais e seus currículos.

Pelas interlocuções mantidas com o Executivo catarinense, mostradas nas três ações episódicas mencionadas no início deste artigo, observa-se a convergência à ideia de vincular o cargo de bibliotecário ao Quadro dos professores tendo em vista que a atuação do bibliotecário na escola aproxima-se daquela realizada pelo docente.

Essa atuação Ihe exigirá atribuições demandas pelo contexto específico da educação básica, atribuições que, acredita-se, o levarão a desenvolver competências que ampliarão àquelas referentes à formação inicial desse profissional, haja vista as demandas observadas nos processos de ensino e aprendizagem, cenário em que se percebe o profissional bibliotecário como partícipe ativo, ou seja, agente de mudanças.

Os três níveis de atuação bibliotecária no modelo de rede aqui trazido e já apresentado ao Executivo catarinense, representado pela Secretaria de Estado da Educação, são entendidos como relevantes para a sustentação de uma rede de bibliotecas escolares de grande porte como as estaduais. Nela o bibliotecário gestor manteria estreita relação com as diretorias de ensino da Secretaria de Educação, principalmente, com a Diretoria de Educação Básica e Profissional (DIEB) e suas gerências de Ensino Fundamental (GEREF), de Ensino Médio (GEREM), de Educação Profissional (GEDUP) e de Educação de Jovens e Adultos (GEREJ), participando e opinando sobre a aplicação dos diferentes programas das esferas federal e estadual relacionados às políticas de leitura, de pesquisa, de dinamização das bibliotecas, de uso e transformação da informação. 0 bibliotecário técnico ficaria centrado na organização das coleções da biblioteca de cada escola, e o bibliotecário educador, dinamizaria o uso das coleções, das tecnologias de comunicação e acesso à informação, se envolveria com as atividades culturais, recreativas e de pesquisa, incentivando o aluno para a leitura e para o uso da biblioteca, o orientando sobre a operacionalização das fontes de informação, prática fundamental para a apropriação da informação e construção de conhecimento.

Contudo, apesar desses entendimentos e esforços, até hoje a Secretaria de Estado da Educação não deu parecer sobre o projeto 
apresentado pela comissão formada pela categoria profissional bibliotecária, do qual um pequeno recorte foi explicitado neste artigo.

Logo, em Santa Catarina há questões fundantes e, ainda, pendentes, para o cumprimento da lei 12.244/2010: a) o poder público precisa instituir o cargo de bibliotecário para atender aos estabelecimentos escolares desassistidos de biblioteca, aqueles que as possuem precariamente e, ainda, aqueles que as possuem, mas cujos serviços precisam ser melhorados; b) é preciso abrir concurso, contratar bibliotecários para as escolas; c) é preciso diagnosticar a estrutura das escolas, estudar e debater sobre o funcionamento de uma grande rede de bibliotecas escolares; d) é preciso ainda, vislumbrar como ficará a prática bibliotecária na prática da escola - será ela mais técnica ou mais pedagógica? Ou a mescla das duas? $\mathrm{E}$ isso tem relação com 0 desenvolvimento da competência bibliotecária na escola; e) o bibliotecário escolar precisa ser amparado pela unidade escolar (diretor, equipe pedagógica e professores), para juntos traçarem as estratégias de atuação da biblioteca e do bibliotecário no conjunto da escola; f) o bibliotecário precisará conhecer e participar das políticas da escola para oferecer melhores serviços bibliotecários, colaborando no estímulo ao uso da biblioteca, à leitura e à pesquisa no meio escolar.

A crescente demanda por biblioteca escolar, os três anos que se passaram, dos dez para que a Lei $12.244 / 2010$ seja cumprida, e a lentidão para o seu cumprimento nos faz pensar: será preciso deixar expirar o prazo de dez anos para se exigir um posicionamento do poder público? Acredita-se que não e este artigo é resultado desse entendimento. Afinal, como convencer o acadêmico e o bibliotecário (e será que apenas este profissional?) da importância de estarem na biblioteca escolar se há, diante deles, uma porta fechada tardando sua inserção na escola? Repercutirá nisso a questão salarial também detalhada no projeto desenvolvido pela categoria bibliotecária catarinense.

Não é demasiado lembrar que a ideia deste texto é a de buscar interlocutores numa conversa sobre biblioteca escolar, no intuito de que essa conversa produza eco. Ao se trazer essas questões para discussão, está-se compreendendo o bibliotecário numa ecologia de profissões, conforme apontado por Cunha; Crivellari (2004), num sistema de interação dessa profissão com outras. É nessa ecologia, que as profissões defendem, ampliam ou perdem espaços de atuação. Quanto a esse movimento são oportunas as palavras de Friedson (1998, p. 247) quando afirma que "os profissionais desenvolvem interesse intelectual por seu trabalho, e, por isso, estão preocupados com sua ampliação e refinamento e acreditam em seu valor para a sociedade." É preciso, então, colocar em evidência as ações da categoria profissional, contar os seus movimentos, as suas interlocuções, os projetos e resultados alcançados. Com isso registra-se parte de uma história, propagam-se ideias, aumentam-se as interlocuções, garante-se a caminhada. 


\section{Referências}

BRASIL. Lei no 12.244, de 24 de maio de 2010. Dispõe sobre a universalização das bibliotecas nas instituições de ensino do País. Diário Oficial [da] República Federativa do Brasil, Brasília, DF, 25 maio 2010. Disponível em: <http://www.planalto.gov.br/ccivil 03/ Ato20072010/2010/Lei/L12244.htm>. Acesso em: 05 jan. 2011.

CAMPELLO, Bernadete Santos. Letramento informacional no Brasil: práticas educativas de Bibliotecários em escolas de ensino básico. Enc. Bibli: R. Eletr. Bibliotecon. Ci. Inf., Florianópolis, v. 15, n. 29, p. 184-208, 2010. Disponível em:

$<$ http://www.periodicos.ufsc.br/index.php/eb/article/view/15182924.2010v15n29p184/19549>. Acesso em: 20 mar. 2013.

O movimento da competência informacional: uma perspectiva para o letramento informacional. Ci. Inf., Brasília, v. 32, n. 3, p. 28-37, set./dez., 2003. Disponível em: <http://revista.ibict.br/ciinf/index.php/ciinf/article/view/26/22>. Acesso em: 10 mar. 2013.

CUNHA, Miriam Vieira da. As profissões e as suas transformações na sociedade. In: CUNHA, Miriam Vieira da; SOUZA, Francisco das Chagas de. Comunicação, gestão e profissão: abordagens para o estudo da Ciência da Informação. Belo Horizonte: Autêntica, 2006.

CUNHA, Miriam Vieira da; CRIVELLARI, Helena Maria Tarchi. O mundo do trabalho na sociedade do conhecimento e os paradoxos das profissões da informação. In: VALENTIM, Marta Lígia Pomim (Org.). Atuação profissional na área de informação. São Paulo: Polis, 2004. cap. 2, p. 39-54.

DINIZ, Marli. Os donos do saber: profissões e monopólios profissionais. Rio de Janeiro: Revan, 2001.

DUDZIAK, Elisabeth Adriana. Information literacy: princípios, filosofia e prática. Ci. Inf., Brasília, v. 32, n. 1, p. 23-35, jan./abr., 2003. Disponível em: <http://revista.ibict.br/ciinf/index.php/ciinf/article/view/123/104>. Acesso em: 21 mar. 2013.

FREIDSON, Eliot. Renascimento do profissionalismo: teoria, profecia e política. São Paulo: Edusp, 1998. 
GARCEZ, Eliane Fioravante; CUNHA, Miriam Vieira da. O bibliotecário na escola de Educação Básica a partir de depoimentos de profissionais de Santa Catarina. Inf. \& Soc., João Pessoa, v. 21, n. 2, p. 121-131, maio/ago. 2011. Disponível em:

< http://www.ies.ufpb.br/ojs2/index.php/ies/article/view/9725/5985>.

Acesso em: 21 ago. 2013.

GARCIARENA, Nélida Alcira; CONFORTI, Noemí. La evaluación del desempeño del bibliotecario escolar en la agenda del director de la institución educativa. Rev. Interam. Bibliot., Medellin (Colombia), v. 34, n. 2, p. 147-156, 2011. Disponível em:

$<$ http://eprints.rclis.org/16769/1/v34n2a3.pdf>. Acesso em: 21 mar. 2013.

LIBRARY for every school, A. (2010). Disponível em:

$<$ http://translate.google.com.br/translate?hl=pt-

BR\&sl=en\&u=http://www.cla.ca/Content/ContentFolders/NewsReleases/2 010/A LIBRARY FOR EVERY SCHOOL-Proclamation2010.doc\&prev $=/>$. Acesso em: 09 mar. 2013.

MACEDO, Neusa Dias de (Org.). Biblioteca escolar brasileira em debate: da memória profissional a um fórum virtual. São Paulo: Senac SP: CRB-8, 2005.

MOREIRO GONZÁLEZ, José Antonio; TEJADA, Carlos. Competencias profesionales en la área de la ciencia de la información. In: VALENTIM, Marta Lígia Pomim (Org.). Atuação profissional na área de informação. São Paulo: Polis, 2004. cap. 6, p. 97-110.

SALES, Fernanda de. O ambiente escolar e a atuação bibliotecária: o olhar da educação e o olhar da biblioteconomia. Enc. Bibli: R. Eletr. Bibliotecon. Ci. Inf., Florianópolis, n. 18, p. 40-56, 2004.

SANTA CATARINA. Assembleia Legislativa. Relatório e voto ao projeto de Lei Complementar no PCL/0039.0/2010. Disponível em: $<$ http://alesc.sc.gov.br/proclegis/tramitacao.php>. Acesso em: 22 jun. 2012.

Procuradoria Geral do Estado. Parecer 0031/11, de 6 de janeiro de 2011. (Cópia fornecida pelo Centro de Memória, da Coordenadoria de Documentação, da Assembleia Legislativa do Estado de Santa Catarina ALESC). 
Secretaria de Estado Da Educação e Inovação. Diretoria de Recursos Humanos. Portaria no 003/SED de 04/04/2003. Dispõe sobre o pessoal para desenvolver atividades administrativas nas EEB - EEB - EEF da rede estadual de ensino. Diário Oficial [do Estado de Santa Catarina], Florianópolis, p. 2, 08 abr. 2003.

SILVA, Waldeck Carneiro da. Miséria da biblioteca escolar. 2. ed. São Paulo: Cortez, 1999. (Questões da Nossa História, 45). 